\title{
Hyperornithinaemia-hyperammonaemia- homocitrullinuria syndrome: a treatable genetic liver disease warranting urgent diagnosis
}

\author{
Hencher HC Lee, KH Poon, CK Lai, KM Au, TS Siu, Judy PS Lai, Chloe M Mak, YP Yuen, \\ CW Lam *, Albert YW Chan
}

\begin{abstract}
A B S T R A C T
Hyperornithinaemia-hyperammonaemiahomocitrullinuria syndrome is an autosomal recessive disorder caused by a defect in ornithine translocase. This condition leads to variable clinical presentations, including episodic hyperammonaemia, hepatic derangement, and chronic neurological manifestations. Fewer than 100 affected patients have been reported worldwide. Here we report the first two cases in Hong Kong Chinese, who were compound heterozygous siblings for c.535C $>$ T (p.Arg179*) and c.815C > T (p.Thr272Ile) in the SLC25A15 gene. When the mother refused prenatal diagnosis for the second pregnancy, urgent genetic testing provided the definitive diagnosis within 24 hours to enable specific treatment. Optimal management of these two patients relied on the concerted efforts of a multidisciplinary team and illustrates the importance of an expanded newborn screening service for early detection and treatment of inherited metabolic diseases.
\end{abstract}

Hong Kong Med J 2014;20:63-6

DOI: $10.12809 / \mathrm{hkmj} 133826$

${ }^{1}$ HHC Lee, MA, FRCPA

${ }^{2}$ KH Poon, FHKAM (Paediatrics)

${ }^{1} \mathrm{CK}$ Lai, MSC

KM Au, MSc

${ }^{3}$ TS Siu, MPhil

${ }^{4}$ JPS Lai, MSc

${ }^{1}$ CM Mak, PhD, FHKAM (Pathology)

${ }^{1}$ YP Yuen, MSc, FHKAM (Pathology)

${ }^{5}$ CW Lam *, PhD, FHKAM (Pathology)

AYW Chan, MD, FHKAM (Pathology)

Department of Pathology, Princess Margaret Hospital, Laichikok, Hong Kong

${ }^{2}$ Department of Paediatrics and Adolescent Medicine, Tuen Mun Hospital, Tuen Mun, Hong Kong

${ }^{3}$ Division of Clinical Biochemistry, Queen Mary Hospital, Pokfulam, Hong Kong

${ }^{4}$ Department of Clinical Pathology, Tuen Mun Hospital, Tuen Mun, Hong Kong

${ }^{5}$ Department of Pathology, The University of Hong Kong, Queen Mary Hospital, Pokfulam, Hong Kong

* Corresponding author: ching-wanlam@pathology.hku.hk

\section{Introduction}

The urea cycle is the major pathway of nitrogen metabolism in the human body. Excess nitrogen, in the form of ammonia, is converted via this cycle to urea and excreted through the kidneys. In humans, the cycle entails five key enzymes, including carbamoyl-phosphate synthetase I (CPS1), ornithine transcarbamylase (OTC), argininosuccinate synthetase, argininosuccinate lyase, and arginase; while an additional enzyme named $\mathrm{N}$-acetylglutamate synthase provides CPS1 with its essential cofactor. ${ }^{1}$ A defect in any of these six enzymatic pathways or the two associated transporters, namely citrin and ornithine translocase, causes urea cycle disorders. ${ }^{2}$ Patients with complete deficiency of the affected enzyme present with significant hyperammonaemia in the neonatal period. It is a serious and often lethal condition or causes irreversible brain damage especially when the diagnosis or treatment is delayed or ineffective. On the other hand, patients with partial enzyme deficiencies or defective transporters can present later in life, from infancy to adulthood, and manifest whenever the urea cycle is overwhelmed by environmental triggers or stresses. These result in acute hyperammonaemic episodes. ${ }^{2}$

Hyperornithinaemia-hyperammonaemiahomocitrullinuria syndrome (HHH syndrome; MIM\#238970) is an autosomal recessive disorder caused by a defect in ornithine translocase (SLC25A15 or ORNT1, MIM*603861). The disorder is exceedingly rare; with fewer than 100 patients having been reported worldwide, although its incidence in northern Saskatchewan in Canada was estimated to be 1 in 1500 (with a carrier rate of 1 in 19). ${ }^{3}$ The syndrome was first described by Shih et $\mathrm{al}^{4}$ in 1969 with a neurological phenotype entailing seizures and mental retardation. It was later found that the clinical presentations of $\mathrm{HHH}$ syndrome can be highly variable, and include spastic paraplegia, pyramidal and extrapyramidal signs, stroke-like episodes, hypotonia, seizures, ataxia, protein intolerance, failure to thrive, and hepatic failure. ${ }^{5-7}$ Liver biopsies typically reveal vacuolated hepatocytes distended with glycogen on light microscopy and bizarre-looking mitochondria on electronic microscopy. ${ }^{8}$ So far, no definite genotypephenotype correlation has been noted, with a high 


\section{高鳥胺酸血症一高氨血症一高瓜胺酸血綜合 症：一種可治癒但須及早診斷的遺傳性肝臟病 \\ 李漢芝、潘建雄、賴志剛、區鑑明、蕭德成、黎寶珊、 \\ 麥 苗、袁月冰、林青雲、陳恩和}

高鳥胺酸血症一高氨血症一高瓜胺酸血綜合症 $(H H H)$ 是一種常染 色體隱性遺傳疾病, 因鳥胺酸轉位酶的缺陷而導致不同的臨床表現, 包括偶發性高氨血症、肝功能紊亂和慢性神經系統表現。受影響的患 者全球只有不足 100 個。本文報告具複合雜合性基因突變的兩名香港 華裔兄弟, 他們的SLC 25A15基因均出現c.535C $>\mathrm{T}$ (p.Arg 179*) 和 c. $815 \mathrm{C}>\mathrm{T}$ （p.Thr272Ile）兩種突變。由於母親第二次懷孕時拒絕作 產前診斷, 當第二名兒子出生時須作緊急基因檢測, 最終在24小時內 作出診斷並施以針對性治療。要治理這兩名患者有賴跨學科小組的共 同努力。本病例㘓明了擴大新生兒篩查服務對於盡早診斷及醫治遺傳 代謝疾病尤為重要。

degree of clinical heterogeneity even among patients harbouring the same genetic defect. ${ }^{9}$ However, patients with $\mathrm{HHH}$ syndrome can respond well to a low-protein diet with improvements in neurological symptoms and hepatic function, for which reason an accurate diagnosis is critical to management. ${ }^{5,10}$ For the first time in Hong Kong, here we describe $\mathrm{HHH}$ syndrome in a pair of siblings and their clinical, biochemical, and molecular profiles, with a view to facilitate understanding of this disorder in our

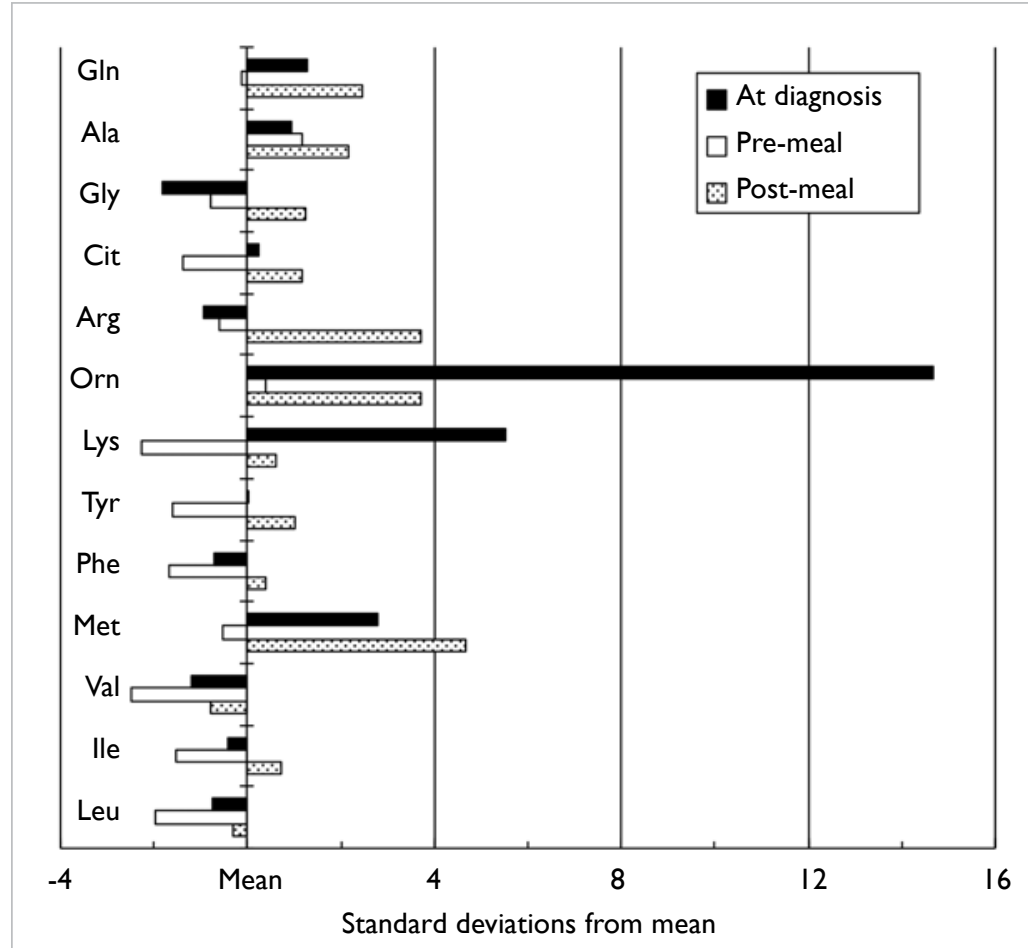

FIG. The amino acid profile of the proband on different occasions

Black bar = pre-treatment at diagnosis; white bar = pre-meal sample; shaded bar = 3 hours post-meal sample. Levels of selected amino acids at diagnosis: glutamine 723

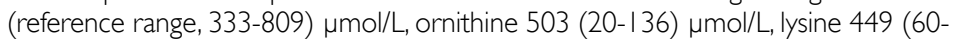
270) $\mu \mathrm{mol} / \mathrm{L}$, and methionine 49 (I3-43) $\mu \mathrm{mol} / \mathrm{L}$ locality. The diagnosis of this family also revealed a possible founder mutation in ethnic Chinese.

\section{Case report}

The patient was an ethnic Han Chinese boy, born healthy to a non-consanguineous couple and fed on both human and formula milk in 2007. He presented with neonatal jaundice with serum bilirubin up to 338 $\mu \mathrm{mol} / \mathrm{L}$ (diazo method) or $295 \mu \mathrm{mol} / \mathrm{L}$ (photometric method) on day 5, which dropped to $179 \mu \mathrm{mol} / \mathrm{L}$ (photometric method) on day 6 after phototherapy. He was then discharged without further blood taking, since otherwise he was clinically well. However, 1 month later he presented with persistent jaundice and a liver palpable $2 \mathrm{~cm}$ below the costal margin but no clinical splenomegaly. The total bilirubin was $99 \mu \mathrm{mol} / \mathrm{L}$ with a direct bilirubin of 27 (reference range [RR], 1-5) $\mu \mathrm{mol} / \mathrm{L}$ and an alkaline phosphatase (ALP) of 529 (RR, 82-383) U/L. His $\gamma$-glutamyltransferase (GGT) ranged from 345 to 388 (reference level, <220) U/L but the alanine transaminase (ALT) was normal at 32 to 35 (RR, 4-35) U/L. While his bilirubin and GGT levels gradually normalised at 2 months, even at 12 months the ALT remained elevated at $311 \mathrm{U} / \mathrm{L}$ and the ALP was $418 \mathrm{U} / \mathrm{L}(\mathrm{RR}, 104-345 \mathrm{U} / \mathrm{L})$. A deranged clotting profile with a prothrombin time of 20.5 (RR, 10.412.6; international normalised ratio, 2.0) seconds, an activated partial thromboplastin time of 36.3 (RR, 26.4-35.3) seconds, and a serum bile acid level of 10.8 (reference level, <7) $\mu \mathrm{mol} / \mathrm{L}$ were noted. At this juncture, his liver remained palpable, $1 \mathrm{~cm}$ below the costal margin. In addition, he was noted to have alpha thalassaemia trait.

At the age of 11 months, gas chromatographymass spectrometry of urine detected significant hyperexcretion of uracil and moderately excessive excretion of orotic acid, while he was taking an unrestricted protein diet (approximately $3 \mathrm{~g} / \mathrm{kg} /$ day). He also had homocitrullinuria of up to 71 (reference level, <9) $\mu \mathrm{mol} / \mathrm{mmol}$ creatinine, which was also demonstrated by liquid chromatography-tandem mass spectrometry. Plasma amino acids analysis by high-performance liquid chromatography detected excessive alanine, arginine, ornithine, and methionine concentrations, postprandially (Figure). At the age of 12 months, the blood ammonia was elevated at 132 (RR, 16-60) $\mu \mathrm{mol} / \mathrm{L}$, the simultaneous blood glucose was $3.8 \mathrm{mmol} / \mathrm{L}$, and the lactate was 2.5 (RR, 0.5-2.2) $\mathrm{mmol} / \mathrm{L}$. The biochemical picture was suggestive of urea cycle dysfunction. Interestingly, at that juncture he was clinically well and had no vomiting or encephalopathy. His blood ammonia decreased to $59 \mu \mathrm{mol} / \mathrm{L}$ on rechecking after 24 hours just before institution of protein restriction $(0.9 \mathrm{~g} / \mathrm{kg} /$ day $)$; over the next 14 days it fluctuated between 43 and $84 \mu \mathrm{mol} / \mathrm{L}$.

Mutational analysis was performed by 
polymerase chain reaction and Sanger sequencing with genomic DNA. While no mutation was noted in the OTC gene, the patient was shown to be heterozygous for two different mutations, c.535C $>\mathrm{T}$ (p.Arg179*) and c.815C $>\mathrm{T}$ (p.Thr272Ile), in the SLC25A15 gene. The latter missense mutation was not found in 100 Chinese control chromosomes tested. Compound heterozygosity was confirmed by analysing the parental DNA.

The patient's liver became impalpable 1 month after therapy. Normalisation of the serum ALT level was noted 1 month after treatment, although plasma ornithine and urine orotic acid levels remained elevated. Coagulation factor VII and X levels were normal during convalescence. At the age of 6 years, the boy had no acute encephalopathy or pyramidal signs, but did exhibit mild clumsiness and subtle gait ataxia (only evident on tandem walking).

The mother became pregnant 1 year later in 2009 , when the proband was 2 years old. In view of the family history of $\mathrm{HHH}$ syndrome, counselling was provided by the obstetrician early during gestation, yet the parents opted not to obtain a prenatal diagnosis. Prior arrangement was then made with the chemical pathologist to have a semi-urgent molecular diagnosis to facilitate therapy for the neonate if necessary. This younger brother was immediately started on a low protein $(\leq 1.2 \mathrm{~g} / \mathrm{kg} /$ day $)$ diet, which consisted of breastfeeding and a zero-protein formula after delivery. Aged 12 hours, the postprandial blood ammonia was $68 \mu \mathrm{mol} / \mathrm{L}$ (reference level, $<100 \mu \mathrm{mol} / \mathrm{L}$ ) and blood for molecular genetics was sampled simultaneously. The boy only had physiological jaundice and no other signs, but was also soon confirmed to have a compound heterozygous form of the two familial mutations about which the paediatrician was notified within 24 hours of blood sampling. In view of the prompt definitive diagnosis, protein restriction was continued with confidence. His ammonia peaked at $111 \mu \mathrm{mol} / \mathrm{L}$ and then normalised, whilst his ALT level remained normal in the neonatal period. His coagulation factors VII and X levels were also normal. The boy did not have any episodes of acute encephalopathy and developed normally when seen for follow-up at the age of 3 years.

\section{Discussion}

When arginase cleaves arginine in the last step of the urea cycle to produce urea and ornithine, the ornithine translocase enzyme transports cytosolic ornithine back into the mitochondria for subsequent urea cycles in exchange of mitochondrial citrulline. ${ }^{11}$ The gene SLC25A15 was cloned in 1999 and found to account for the $\mathrm{HHH}$ syndrome, ${ }^{12}$ and molecular modelling was reported early in $2012 .{ }^{13}$ A founder mutation p.Phe188del was reported in FrenchCanadian patients, ${ }^{12}$ and in Japanese patients the p.Arg179* mutation was also noted to be frequent. ${ }^{14,15}$
The nonsense mutation p.Arg179* variant is predicted to cause premature termination of the protein. Although common in Japan, ${ }^{14}$ it was also reported in other ethnic groups. ${ }^{15}$ The missense mutation p.Thr272Ile was reported in 2009 by Tessa et $\mathrm{al}^{15}$ in one Taiwanese patient, with recently published functional proof of its pathogenicity. However, this missense mutation has never been reported in other ethnic groups. We therefore postulate that it could be a common mutation, possibly having an ancestral founder gene effect in ethnic Chinese. If this is confirmed in more patients of Chinese ethnicity, it may aid prioritising workflow for the genetic testing of individuals suspected to have $\mathrm{HHH}$ syndrome. In which case, they could undergo more focused molecular investigation instead of whole gene sequencing. Consequently, a more rapid diagnosis could enable more prompt and appropriate treatment.

To the best of our knowledge, these were the first two cases of $\mathrm{HHH}$ syndrome reported in Hong Kong. The proband's metabolic profile in early infancy was particularly illustrative of the natural course of the associated hepatic disease. The untreated first child had pronounced neonatal jaundice which responded to phototherapy and soon evolved into mild transient hyperbilirubinaemia with an accompanying elevation in serum ALP but not ALT levels in early infancy. Subsequently, despite resolution of jaundice, he showed moderate hepatocellular derangement and dysfunction with a coagulopathy and hyperammonaemia, which responded to protein restriction. The younger brother had no serum ALT level elevation while the ammonia level was only mildly raised in the first week of life, at which time he was proactively commenced on protein restriction. These two cases demonstrate that metabolic profiling, including the ammonia level, should be included in the initial workup for any infant with unexplained prolonged liver dysfunction and may provide a clue to a possible underlying defect in the urea cycle. The $\mathrm{HHH}$ syndrome is rare, yet a readily treatable cause to consider in Chinese patients with unusual plasma amino acid patterns. In addition, modern medical technologies (eg tandem mass spectrometry) allow multiplex screening of classical inherited metabolic disorders that can detect $\mathrm{HHH}$ syndrome using hyperornithinaemia as the disease marker. ${ }^{16}$ The successful diagnosis and management of these siblings entailed a concerted effort and collaboration of a multidisciplinary team. Notably, the diagnosis of rare diseases is often difficult, and the importance of having an integrated pathology service is crucial.

Prenatal diagnosis for the younger brother was possible but declined by the parents, making timely intervention of the chemical pathology laboratory even more critical for establishing or excluding the 
diagnosis in the neonate. In this clinical setting, a rapid and definitive diagnosis (within 24 hours) provided by genetic testing was important as a mildly elevated ammonia level in an asymptomatic newborn may be hard to interpret. It allowed the clinicians to counsel the parents accordingly on the need for lifelong protein restriction to minimise the chance of decompensation. Although lateonset long-term neurological sequelae may not be preventable, ${ }^{9}$ it is prudent to keep the two children metabolically stable as far as possible, to mitigate brain damage from decompensation.

In conclusion, $\mathrm{HHH}$ syndrome, although very rare, is an inborn error of metabolism that can occur in the Chinese and is readily detectable by tandem mass spectrometry. ${ }^{17}$ If this technique could be introduced to support a local newborn screening programme, many more possibly treatable metabolic disorders may be picked up.

\section{References}

1. Häberle J. Clinical practice: the management of hyperammonemia. Eur J Pediatr 2011;170:21-34.

2. Mitchell S, Ellingson C, Coyne T, et al. Genetic variation in the urea cycle: a model resource for investigating key candidate genes for common diseases. Hum Mutat 2009;30:56-60.

3. Sokoro AA, Lepage J, Antonishyn N, et al. Diagnosis and high incidence of hyperornithinemia-hyperammonemiahomocitrullinemia ( $\mathrm{HHH})$ syndrome in northern Saskatchewan. J Inherit Metab Dis 2010;33 Suppl 3:275-81.

4. Shih VE, Efron ML, Moser HW. Hyperornithinemia, hyperammonemia, and homocitrullinuria. A new disorder of amino acid metabolism associated with myoclonic seizures and mental retardation. Am J Dis Child 1969;117:83-92.

5. Al-Hassnan ZN, Rashed MS, Al-Dirbashi OY, Patay Z, Rahbeeni Z, Abu-Amero KK. Hyperornithinemiahyperammonemia-homocitrullinuria syndrome with stroke-like imaging presentation: clinical, biochemical and molecular analysis. J Neurol Sci 2008;264:187-94.

6. Lemay JF, Lambert MA, Mitchell GA, et al. Hyperammonemia-hyperornithinemia-homocitrullinuria syndrome: neurologic, ophthalmologic, and neuropsychologic examination of six patients. J Pediatr 1992;121:725-30.

7. Gatfield PD, Taller E, Wolfe DM, Haust MD. Hyperornithinemia, hyperammonemia, and homocitrullinuria associated with decreased carbamyl phosphate synthetase I activity. Pediatr Res 1975;9:488-97.

8. Haust MD, Gordon BA. Ultrastructural changes in the mitochondria in disorders in ornithine metabolism. Pediatr Res 1980;14:1411.

9. Debray FG, Lambert M, Lemieux B, et al. Phenotypic variability among patients with hyperornithinaemiahyperammonaemia-homocitrullinuria syndrome homozygous for the delF188 mutation in SLC25A15. J Med Genet 2008;45:759-64.

10. Gjessing LR, Lunde HA, Undrum $\mathrm{T}$, Broch $\mathrm{H}$, Alme A, Lie SO. A new patient with hyperornithinaemia, hyperammonaemia and homocitrullinuria treated early with low protein diet. J Inherit Metab Dis 1986;9:186-92.

11. Palmieri F. The mitochondrial transporter family (SLC25): physiological and pathological implications. Pflugers Arch 2004;447:689-709.

12. Camacho JA, Obie C, Biery B, et al. Hyperornithinaemiahyperammonaemia-homocitrullinuria syndrome is caused by mutations in a gene encoding a mitochondrial ornithine transporter. Nat Genet 1999;22:151-8.

13. Wang JF, Chou KC. Insights into the mutation-induced $\mathrm{HHH}$ syndrome from modeling human mitochondrial ornithine transporter-1. PLoS One 2012;7:e31048.

14. Miyamoto T, Kanazawa N, Kato S, et al. Diagnosis of Japanese patients with HHH syndrome by molecular genetic analysis: a common mutation, R179X. J Hum Genet 2001;46:260-2.

15. Tessa A, Fiermonte G, Dionisi-Vici C, et al. Identification of novel mutations in the SLC25A15 gene in hyperornithinemia-hyperammonemia-homocitrullinuria $(\mathrm{HHH})$ syndrome: a clinical, molecular, and functional study. Hum Mutat 2009;30:741-8.

16. Chace DH, Kalas TA, Naylor EW. Use of tandem mass spectrometry for multianalyte screening of dried blood specimens from newborns. Clin Chem 2003;49:1797-817.

17. Lee HC, Mak CM, Lam CW, et al. Analysis of inborn errors of metabolism: disease spectrum for expanded newborn screening in Hong Kong. Chin Med J (Engl) 2011;124:9839. 